\title{
A study on the impact of the quality of management education on the new economy-knowledge: Evidence from members of OIC countries
}

\author{
Maryam Yokhaneh $^{\mathrm{a}^{*}}$ and Rafik Baghoumian ${ }^{\mathrm{b}}$
}

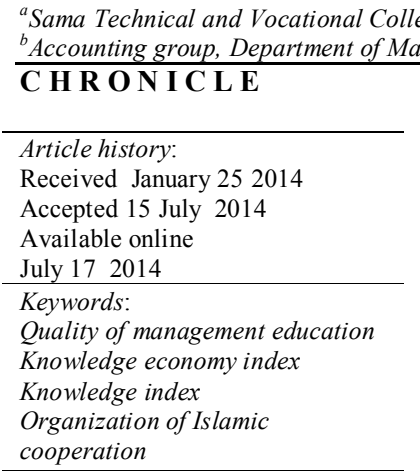

This paper studies the effects of Quality of Management Education (QME) at universities on knowledge creation, application and distribution in knowledge based economy(KEI). The study also investigates the influence of QME on effective use of knowledge in economic development(KI).Using some regression technique, the study has determined a positive relationship of the effects of QME on KEI and KI in members of organization of Islamic cooperation (OIC). In addition, the study investigates the position of Iran in terms of quality of management education and the level of knowledge based economy.

\section{Introduction}

Measuring the effects of educational programs on development of economy has been an interesting area of research for the past few years (Srikanthan \& Dalrymple, 2004; Becket \& Brookes, 2008; Leung, 2004; Cox et al., 2010). Srikanthan and Dalrymple (2007), for instance, developed an overarching basis to consider issues of quality in higher education. They concluded that it could be possible to synthesize a model, based on existing literature, to address higher education, more uniquely. Knowledge economy, on the other hand, plays essential role for sustainable economic development (Chen \& Dahlman, 2005) and to measure the important factors influencing on knowledge economy, we may consider various factors such as Knowledge Economy Index (KEI) and Knowledge Index (KI) (Jaffe \& Trajtenberg, 2002). Powell and Snellman (2004) defined the knowledge economy as production and services based on knowledge-intensive activities, which contribute to an accelerated pace of technical and scientific advance, as well as rapid obsolescence. The key component of a knowledge economy is a bigger reliance on intellectual capabilities than on physical inputs or natural resources. They provided evidence drawn from patent data to document an

E-mail addresses: marinayokhaneh@gmail.com (M. Yokhaneh) 
upsurge in knowledge production and explained that this expansion could be driven by the emergence of new industries. They also reviewed the contentious literature, which evaluates whether recent technological advances had raised, productivity. They also shed light on the debate over whether new forms of work that embody technological change had generated more worker autonomy or bigger managerial control (Wankel \& Stoner, 2009). Moreover, they evaluated the distributional consequences of a knowledge-based economy in terms of growing inequality in wages and highquality jobs.

Wright et al. (2013) presented the findings of a 'Knowledge Economy Market Development Mapping Study' conducted to detect the value of design education programs from primary through to tertiary level in Queensland, Australia. They also explored the relationship of these programs to the development of the capacities mentioned above. Their investigation included the collection of qualitative and quantitative data as well as focus groups and survey. Noel and Qenani (2013) examined the emerging paradigm of skills perceived as essential in the knowledge economy by applying a choice experiment. They recommended a shift in the requirements for skills of agribusiness graduates with skills such as creativity and critical thinking becoming quite important in the labor market.

Akram et al. (2013) examined and elaborated the relationship between knowledge management process and innovation process to determine the important relationships and flows of activities. They reported that various components of Knowledge Management as Knowledge activities, Knowledge types, transformation of knowledge and technology had a positive impact in bringing innovation through transformation of knowledge into knowledge assets in organizations. In their study, the innovative aspect of the study was that all knowledge management activities were incorporated simultaneously to examine their impact on innovation.

Mohamed et al. (2006) investigated the role of information technology (IT) in knowledge extraction, capture, distribution and personalization. They also tried to determine the strengths and weaknesses of IT in the domain of knowledge management (KM) and to explain why the technology promise remains unfulfilled, as observed by many KM practitioners.

\section{The proposed study}

This paper studies the effects of Quality of Management Education (QME) at universities on knowledge creation, application and distribution in knowledge based education. We also measure the effective influence of knowledge on economic development. The study measures the effects of QME on Knowledge Economy Index (KEI) and Knowledge Index(KI). There are two hypotheses with the proposed study of this paper as follows,

1. Quality of Management Education (QME) at universities influences positively on knowledge creation, application and distribution(KEI) .

2. Quality of Management education at universities influences positively on effective use of knowledge in economic development(KI).

The study has been accomplished using regression analysis where there are two dependent variables including KEI and KI and QME is the independent variable. The study collects the necessary information from World Bank Data Base. Fig. 1 demonstrates the position of countries in terms of QME index. 


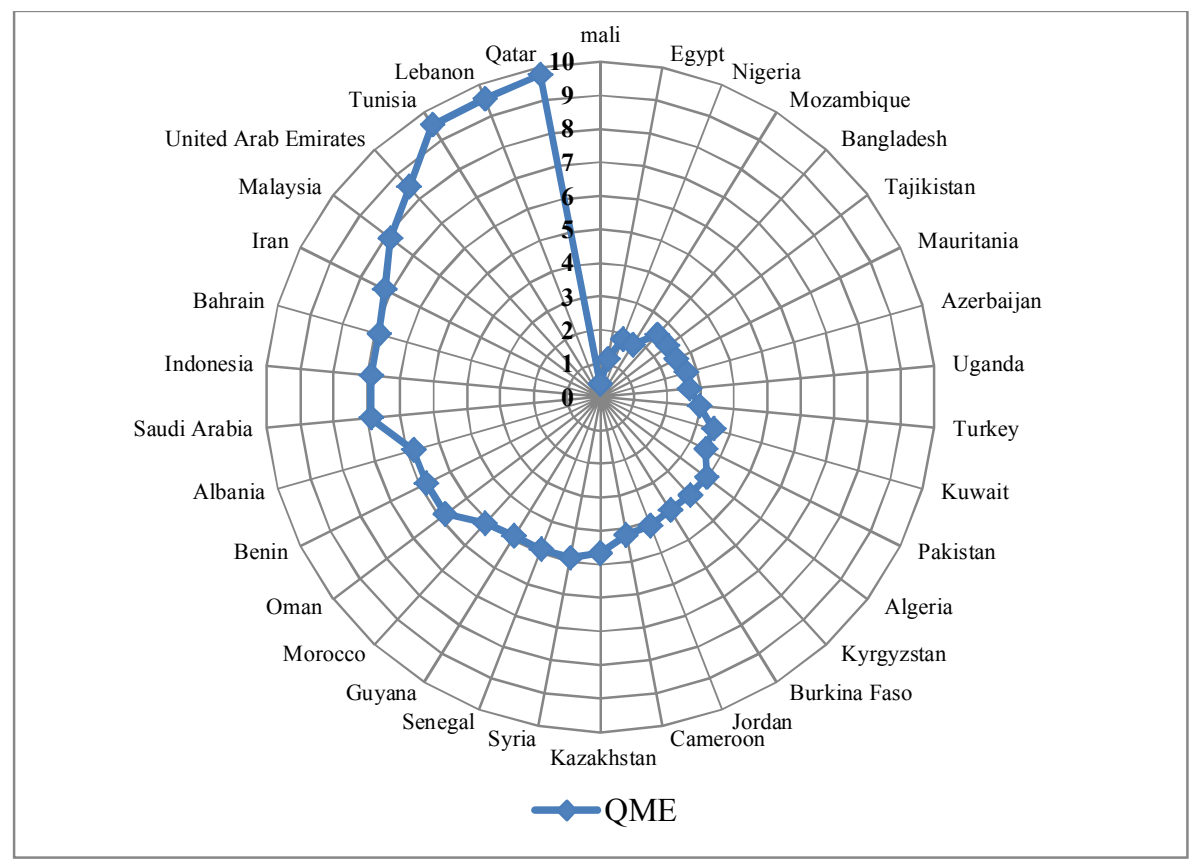

Fig. 1. Position of QME in OIC countries

As we can observe from the results of Fig. 1, while Qatar maintains the highest index (QME = 9.77), Mali maintains the lowest position and Iran has relatively a good position (QME $=7.18)$. In addition, Fig. 2 demonstrates the results of our survey on KEI index.

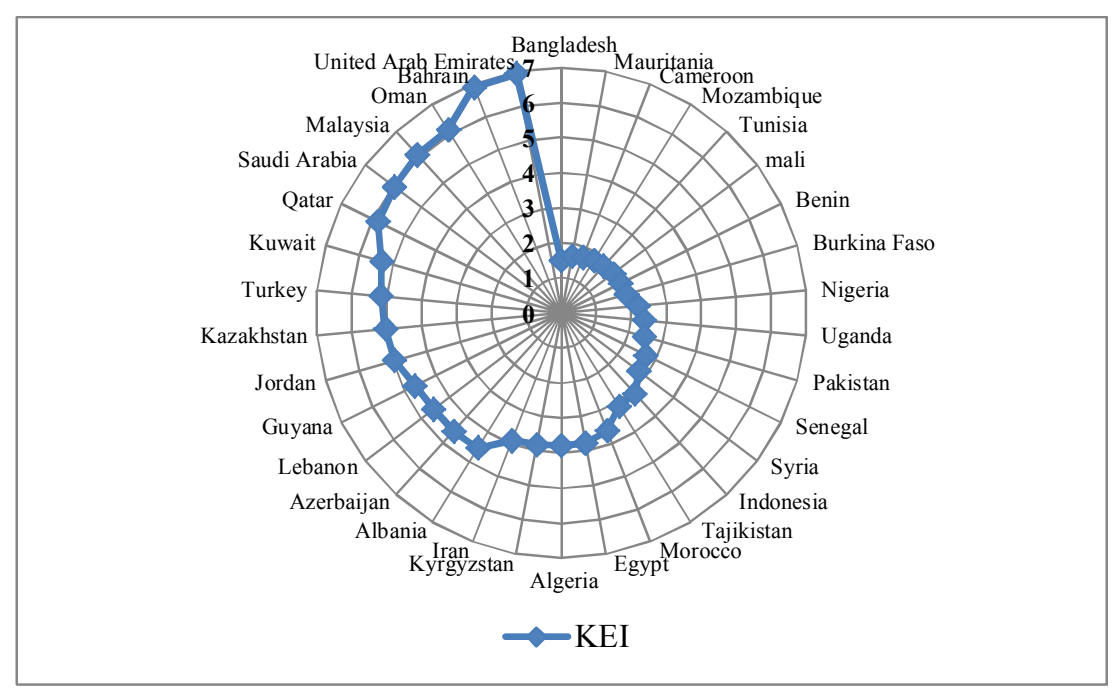

Fig. 2. Position of KEI in OIC countries

As we can observe from the results of Fig. 2, while United Arab Emirates maintains the highest KEI index and Bangladesh has the minimum index. Finally, Fig. 3 demonstrates the results of KI index. 


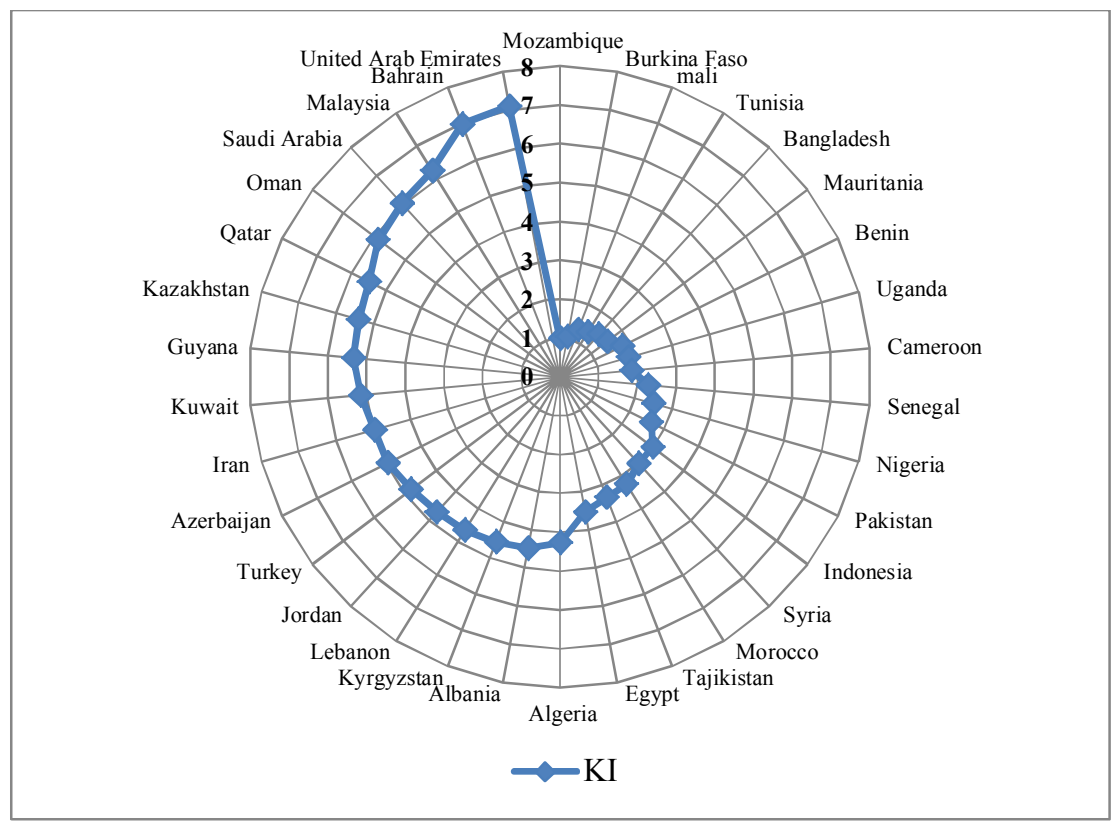

Fig. 3. Position of KI in OIC countries

The propose study uses two regression model to study the effects of KI and KEI on QME. The implementation of Kolmogorov-Smirnov test has indicated that all variables are normally distributed. The Pearson correlation test between QME and KEI and between QME and KI are 0.483 and 0.486, respectively. Since these two correlations are statistically significant, we may reach a preliminary conclusion that there were some positive relationships between QME and KI, KEI.

\section{The results}

In this section, we present details of our findings on implementation of regression analysis.

\subsection{The effects of QME on KEI}

We first investigate the effects of QME on KEI. Table 1 demonstrates the summary of regression analysis.

\section{Table 1}

The summary of regression analysis on the effect of QME on KEI

\begin{tabular}{cccccc}
\hline \multirow{2}{*}{ Model 1 } & \multicolumn{2}{c}{ Non-standard coefficients } & Standard coefficients & \multirow{2}{*}{ t } & \multirow{2}{*}{ Sig. } \\
\cline { 2 - 5 } & $\beta$ & Standard error & $\beta$ & & \\
\hline (Constant) & 2.201 & 0.565 & & 3.893 & 0.000 \\
QME & 0.328 & 0.105 & 0.483 & 3.117 & 0.004 \\
\hline
\end{tabular}

Adjusted R-Square $=0.209$ Durbin-Watson $=1.677$

As we can observe from the results of Table 1, all statistical observations are significant with $\alpha=5 \%$. In addition, the positive sign indicates that QME influences positively on KEI.

\subsection{The effects of $Q M E$ on $K I$}

We now study the impact of QME on KI. Table 2 presents details of our findings on implementation of regression analysis. 
Table 2

The results of the effects of QME on KI

\begin{tabular}{ccccc}
\hline \multirow{2}{*}{ Mode 2 } & \multicolumn{2}{c}{ Non-standard coefficients } & Standard coefficients & Sig. \\
\cline { 2 - 4 } & $\beta$ & Standard error & $\beta$ & 3.330 \\
(Constant) & 2.065 & 0.620 & 0.002 & 3.061 \\
\hline QME & 0.353 & 0.115 & 0.476 & 0.004 \\
\hline Adjusted R-Square $=0.202$ Durbin-Watson $=1.713$ & &
\end{tabular}

Adjusted R-Square $=0.202$ Durbin-Watson $=1.713$

The results of Table 2 also show a positive relationship between KI and QME. Adjusted R-Square is equal to 0.202 , which means changes of QME could approximately describe $20 \%$ of the changes on KI.

\section{Conclusion}

In this paper, we have investigated the effects of Quality of Management Education (QME) at universities on knowledge creation, application and distribution in knowledge based education. We have also measured the effective influence of knowledge on economic development. The study has measured the effects of QME on Knowledge Economy Index (KEI) and Knowledge Index (KI). Using some regression technique, the study determined a positive relationship of the effects of QME on KEI and KI on members of organization of Islamic cooperation (OIC). The results of our survey are consistent with other findings earlier reported by Leung (2004), Noel and Qenani (2013) and Wright et al. (2013).

\section{Acknowledgement}

The authors would like to thank the anonymous referees for constructive comments on earlier version of this paper.

\section{References}

Akram, K., Siddiqui, S. H., Nawaz, M. A., Ghauri, T. A., \& Cheema, A. K. H. (2011). Role of knowledge management to bring innovation: an integrated approach. Cell, 92(333), 6183035.

Becket, N., \& Brookes, M. (2008). Quality management practice in higher education-what quality are we actually enhancing. Journal of Hospitality, Leisure, Sport \& Tourism Education, 7(1), 40-54.

Chen, D. H., \& Dahlman, C. J. (2005). The knowledge economy, the KAM methodology and World Bank operations. World Bank Institute Working Paper, (37256).

Cox, R., Gabris, G. T., \& Levin, M. M. (2010). Educating local government managers for the twentyfirst century: A preface to the symposium. Journal of Public Affairs Education, 16(3), 325-336.

Jaffe, A. B., \& Trajtenberg, M. (2002). Patents, citations, and innovations: A window on the knowledge economy. MIT press.

Leung, S. K. (2004, November). Statistics to measure the knowledge-based economy: The case of Hong Kong, China. In Asia Pacific Technical Meeting on Information and Communication Technology (ICT) Statistics, Wellington, November.

Mohamed, M., Stankosky, M., \& Murray, A. (2006). Knowledge management and information technology: can they work in perfect harmony?. Journal of Knowledge Management, 10(3), 103116.

Powell, W. W., \& Snellman, K. (2004). The knowledge economy. Annual Review of Sociology, 30, 199-220.

Noel, J., \& Qenani, E. (2013). New age, new learners, new skills: What skills do agribusiness graduates need to succeed in the knowledge economy?. International Food and Agribusiness Management Review, 16(3), 17-35.

Srikanthan, G., \& Dalrymple, J. (2004). A synthesis of a quality management model for education in universities. International Journal of Educational Management, 18(4), 266-279. 
Srikanthan, G., \& Dalrymple, J. F. (2007). A conceptual overview of a holistic model for quality in higher education. The International Journal of Educational Management, 21(3), 173-193.

Wankel, C., \& Stoner, J. A. F. (Eds.). (2009). Management education for global sustainability. IAP.

Wright, N., Davis, R., \& Bucolo, S. (2013, May). The creative citizen: understanding the value of design education programs in the knowledge economy. In Proceedings of the 2nd International Conference for Design Education Researchers (Volume 4) (Vol. 4, pp. 2230-2248). ABM-media. 